JPE 11-4-18

\title{
Design Considerations for Low Voltage Claw Pole Type Integrated Starter Generator (ISG) Systems
}

\author{
Geun-Ho Lee*, Geo-Seung Choi**, and Woongchul Choi ${ }^{\dagger}$ \\ $\dagger^{*}$ Graduate School of Automotive Engineering, Kookmin University, Seoul, Korea \\ ** Samhyun Co., Changwon, Korea
}

\begin{abstract}
Due to the need for improved fuel consumption and the trend towards increasing the electrical content in automobiles, integrated starter generator (ISG) systems are being considered by the automotive industry. In this paper, in order to change the conventional generator of a vehicle, a belt driven integrated starter generator is considered. The overall ISG system, the design considerations for the claw pole type AC electric machine and a low voltage very high current power stage implementation are discussed. Test data on the low voltage claw pole type machine is presented, and a large current voltage source DC/AC inverter suitable for low voltage integrated starter generator operation is also presented. A metal based PCB (Printed Circuit Board) power unit to attach the 4-parallel MOS-FETs is used to achieve extremely high current capability. Furthermore, issues related to the torque assistance during vehicle acceleration and the generation/regeneration characteristics are discussed. A prototype with the capability of up to $1000 \mathrm{~A}$ and $27 \mathrm{~V}$ is designed and built to validate the kilo-amp inverter.
\end{abstract}

Key Words: Claw pole motor, Integrated starter and generator, Permanent magnet synchronous motor, PWM inverter

\section{INTRODUCTION}

Idle stop and go (ISG) is one of the most important functions of a hybrid electric vehicle (HEV) operating in a heavy traffic area. Idle stop ceases engine operation in order to eliminate fuel consumption and emissions when vehicle is temporally stopped. After an idle stop, the engine is restarted automatically by an electric motor. This system is called an integrated starter generator (ISG) [1]. A belt alternator starter (BAS) system is comprised of an electric machine, power electronics, a controller and a battery. A BAS system is designed to the increase of the fuel economy of a vehicle. Improvements of over $10 \%$ in fuel economy for city drive cycles have been reported in vehicles using BAS systems [2].

The concept of using a single AC machine, as both a starter and a generator, in an integrated starter generator (ISG) system has become popular and appears particularly attractive in automotive applications [3]. In general, the AC machine in an ISG system will operate as a motor to start an engine with a very high torque and then act as a generator at higher speeds for supplying constant power to the DC battery bank or super capacitor. The ISG system and the super capacitor are able to assist engine when the vehicle is accelerating. This small hybrid system using an ISG can be adapted to conventional engine vehicles with only minimal

\footnotetext{
Manuscript received Oct. 21, 2010; revised Apr. 24, 2011

Recommended for publication by Associate Editor Jang-Mok Kim.

$\dagger$ Corresponding Author: danchoi@kookmin.ac.kr

Tel: +82-2-910-5461, Fax: +82-2-910-5351, Kookmin University

* Graduate School of Automotive Engineering Kookmin University, Korea

** Samhyun Co., Korea
}

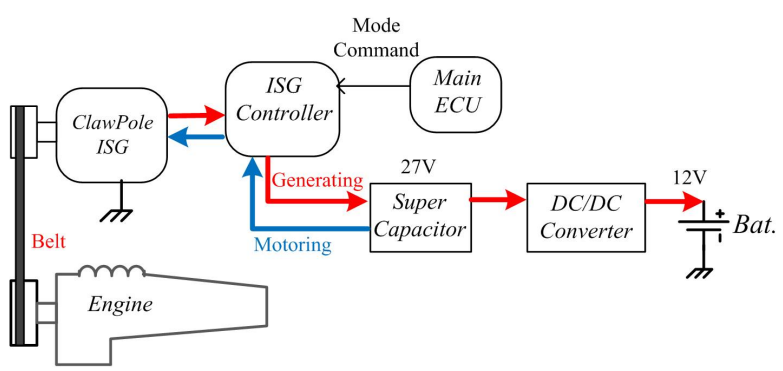

Fig. 1. A structure of belt driven ISG system.

system changes. The structure of a belt driven ISG system is presented in Fig. 1.

Due to the limited engine room space in a conventional vehicle, there are several challenging technical issues that need to be addressed in order to satisfy the torque-speed characteristics for starting, generating and torque assisting, respectively. For the small hybrid system using an ISG, the AC machine will first run as a starter in the speed range of $0-2,000 \mathrm{rpm}$ with a very large starting torque. It can also assist the engine torque at $6,000 \mathrm{rpm}$. Then, from $2,000 \mathrm{rpm}$ to $15,000 \mathrm{rpm}$, the $\mathrm{AC}$ machine switches to generator operation, with a constant power output. Therefore, machine design is very special because the operating torque-speed curve of the AC machine spans a very wide range due to the extreme values of the starting torque and the generating speed. From the view point of the driver, the super capacitor voltage is so low (16 27 V operation) that the current capability is up to 1000 amps [4].

The claw pole type generator has received a great deal of 
attention for automotive applications in belt-driven structures, where robustness and high-speed operations are imposed.

In this paper, an overall ISG system for small hybrid applications and the design considerations for a claw pole type AC electric machine are discussed. A prototype low voltage claw pole machine and a very large current voltage source DC/AC inverter $\left(1,000 \mathrm{~A}_{\text {peak }}, 27 \mathrm{~V}\right)$, which is suitable for use as a low voltage integrated starter generator, are also presented. Issues related to the torque assist under vehicle acceleration, and the generation/regeneration characteristics are discussed

\section{Integrated StARTER Generator System}

\section{A. ISG System Configuration}

An ISG system takes the place of a traditional generator and starter and is located in the place of the generator. Such systems provide the ability to perform engine starting, torque assist, regenerative braking, and continuous generating without requiring large changes to the vehicle. Fig. 1 shows the overall configuration of an ISG system, containing four major parts: a power converter, an AC machine, a super capacitor and a DSP controller. A constraint of the system design is that the DC bus voltage must be in the range of 16-27 V, and it must not be allowed to change. The power circuit for the proposed ISG system is a three phase voltage source inverter using power MOS-FETs in parallel. A buck converter is installed to excite the field coil as shown in Fig. 3. Feedback signals such as currents and voltage are acquired and used by the DSP after passing through a signal conditioning circuit. Based on the feedback information, advanced control algorithms embedded in DSP command the space vector PWM that in turn gates the power inverter for either starter or generator operation.

A claw pole type ISG machine and a VSI-based low voltage ISG driver structure are presented in Fig. 2 and Fig. 3, respectively. The resolver is used to detect the motor control and the slip ring supplies power to the winding coil.

\section{B. Operation Mode}

A belt driven ISG system provides starting, generating, torque assisting and 3-phase PWM converter functions for regenerative braking. During the starter mode, the machine is motoring at a low speed and is self-driven with torque control. It operates at maximum power for sufficiently fast cranking. During this mode, the super capacitor is discharged. The PWM inverter supplies maximum current to the motor and the buck converter excites the field coil with a maximum current.

During the torque assist mode, the machine is motoring at the low torque and high speed and it is self-driven with torque control. It operates at maximum power for sufficiently torque assist as long as the super capacitor voltage is sufficient.

During the generating mode, the converter can be operated in a synchronous rectifier mode, thus authorizing an increase in efficiency. After the starter mode, the ISG system goes in generator mode to supply electric power. After the starter mode, the ISG system is allowed to choose between the standard generator mode and the 3-phase PWM converter mode with torque regulation function. In the standard generator mode the diodes of the 3-phase inverter operate as a
TABLE I

DESIGN SPECIFICATIONS OF ISG SYSTEM

\begin{tabular}{lc}
\hline \multicolumn{1}{c}{ Items } & Value \\
\hline Cold starting torque & $30 \mathrm{Nm}$ \\
Max. starting current & 1,000 Apeak \\
Super capacitor voltage & $16 \sim 27 \mathrm{~V}$ \\
Max. ISG speed & $15,000 \mathrm{rpm}$ \\
Max. generating power & $4 \mathrm{~kW}$ \\
ISG/Engine rpm ratio & 2.5 \\
Min. starting voltage & $16 \mathrm{~V}$ \\
\hline
\end{tabular}

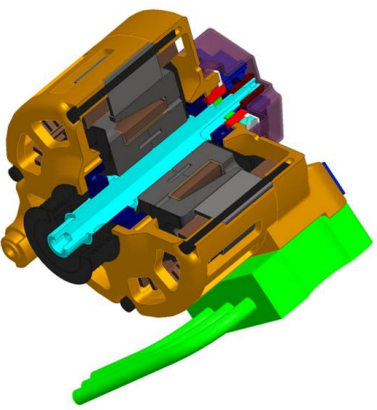

(a) Machine configuration.

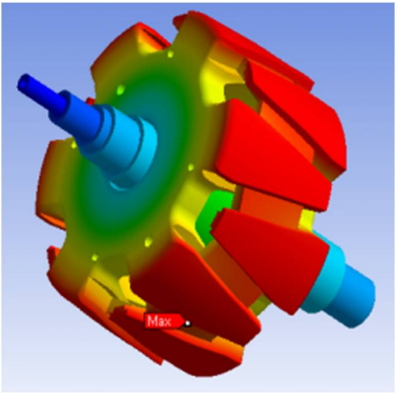

(b) A rotor of claw pole machine.
Fig. 2. A claw pole typed AC machine configuration.

3-phase synchronous rectifier and the super capacitor voltage is regulated by controlling the field current. In the 3-phase PWM converter mode torque regulation is used with a voltage limitation for recovering the maximum amount of energy in the super capacitor with current control.

\section{Claw Pole Type AC Machine for the ISG}

To achieve the performance requirements for an ISG system, the AC electric machine must be carefully designed. To meet the design goals, a claw pole machine is considered and the machine size is constrained so that it can be used as a substitute for a conventional alternator. The popularity of this type of electric machine is mainly due to its high pole pair number which increases the torque density and its robust structure allowing for high speed operation. The machine is equipped with a rotor winding supplied by the slip rings. The machine is to be driven in a manner that is similar to a conventional generator by a belt connected to the engine. The gear ratio is 2.timeMinute1Hour171strans5:1 and it is to be air cooled. Fig. 5 shows an electro-magnetic analysis of a claw pole machine dedicated to an ISG application with maximum field winding. The procedure for designing is not described in this article but it is based on an optimal approach. The main characteristics of the optimal design are summarized in Table I.

TABLE II

A DESIGNED CLAW POLE TYPED AC MACHINE

\begin{tabular}{lc}
\hline \multicolumn{1}{c}{ Items } & Value \\
\hline External dia./length & $\Phi 165 / 188 \mathrm{~mm}$ \\
Air gap & $0.7 \mathrm{~mm}$ \\
EMF & $4 V_{\text {rms }}$ \\
Stator resistance & $3.6 \mathrm{mOhm}$ \\
Inductance $L_{d} / L_{q}$ & $90 / 120 \mu \mathrm{H}$ \\
Stator turns & 4 \\
Pole & 12 \\
Field winding of rotor & 140 turns $/ 1.2 \mathrm{Ohm}$ \\
\hline
\end{tabular}


TABLE III

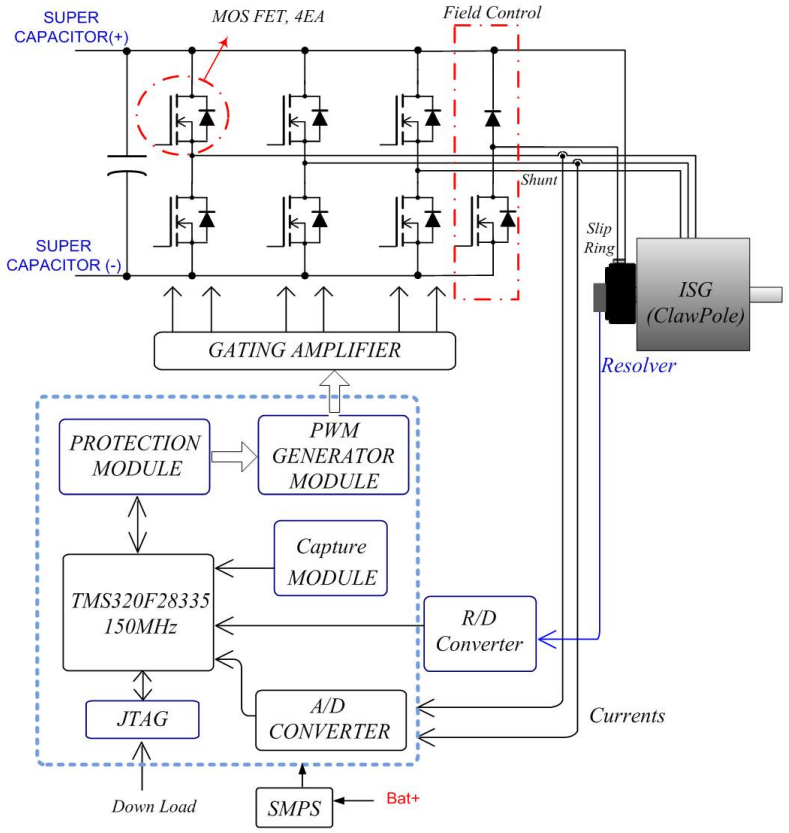

Fig. 3. A claw pole typed ISG controller configuration.

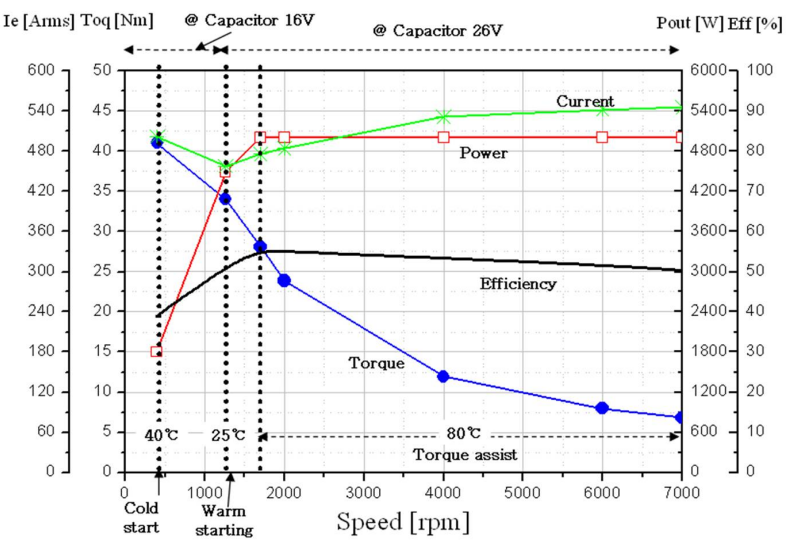

Fig. 4. A designed claw pole typed machine characteristics.
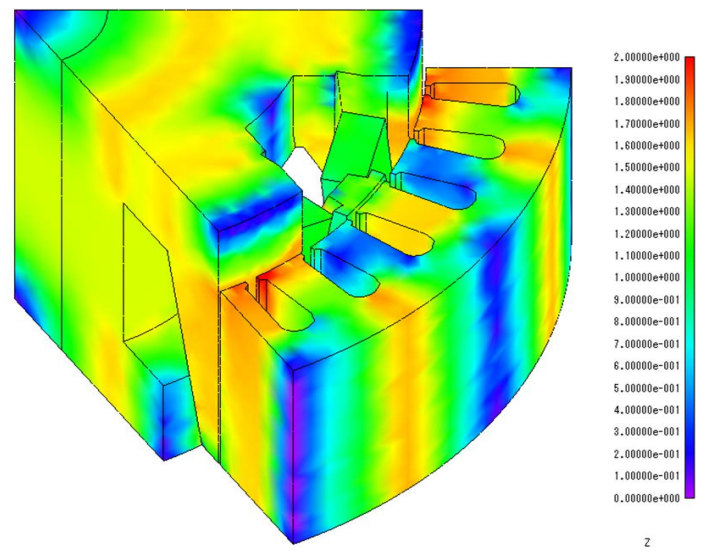

Fig. 5. Electro-magnetic analysis of claw pole ISG machine.
SPECIFICATIONS OF ISG CONTROLLER

\begin{tabular}{lc}
\hline \multicolumn{1}{c}{ Items } & Value \\
\hline MOS-FET & IRFS3107*4 EA Parallel \\
DSP & TMS320F28335 \\
Switching frequency & $20 \mathrm{kHz}$ \\
Current sensor & $0.1 \mathrm{mOhm} * 3 \mathrm{EA} / \mathrm{phase}$ \\
DC link voltage & $16 \sim 27 \mathrm{~V}$ \\
Super capacitor & $200 \mathrm{~F}$ \\
\hline
\end{tabular}

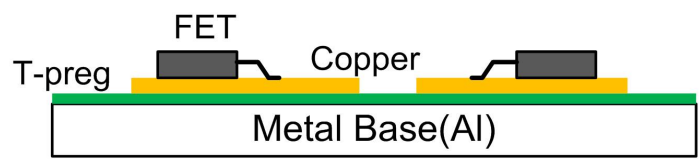

Fig. 6. Structure of metal PCB to attach the MOS-FET.

\section{Drive System for Claw Pole Type AC Machines}

The power board drives the stator and the rotor according to the command signals of the control board. The rotor is excited by a PWM signal generated by the excitation MOS-FET that also produces the rotor current. Depending on the operation mode, the inverter can generate the three phases of the stator or synchronously rectify them to deliver power to the battery and the super capacitor. A VSI-based ISG for the ISG system has to be highly reliable and at the lowest possible cost. Design constraints are imposed in terms of thermal behavior because of compactness.

After many comparison studies on several types of power MOSFETs, IRFS3107 with D2PAK-7 package is chosen for its best ratio of performance to cost. Specifically, the IRFS3107 has the ratings of $75 \mathrm{~V}, 260 \mathrm{~A}$ (peak), $175 C$ junctiontemperature and ultra low on-state resistance $(2.1 \mathrm{mOhm})$. To detect the 3-phase current, three shunt registers $(0.1 \mathrm{mOhm})$ per phase is used and isolated with an isolation amplifier. The most recent floating point digital signal processor, a TMS320F28335 of Texas Instrument, is employed in order to drive the motor. Because of its very low inductance, 20 $\mathrm{kHz}$ switching frequency was chosen to minimize the high frequency current ripple. The thermal design consideration focused on reducing the overall system thermal resistance by enhancing the tight thermal contact between the device case and heat sink. To enhance contact between the MOS-FET case, the heat sink and the isolated MOS-FET drain, a metal PCB is used as in Fig. 6. In the prototype design, a forced air cooled heat sink with the dimensions of 180x190x35 mm is used. A cooling fan is installed to provide forced-air cooling with an air flow rate of $3 \mathrm{~m} / \mathrm{sec}$. The thermal simulation results by FEM (ANSIS) are presented in Fig. 7.

In Table III, the specifications of the ISG controller are presented. The $200 \mathrm{~F}$ super capacitor is installed near the driver.

\section{PROTOTYPE ISG AND EXPERIMENTAL RESULTS}

\section{A. Prototype ISG Machine and Controller}

5 types of machines with different stator coil turns (5 turns, 4 turns, 3.5 turns, 1 turn (Case 2), 1.7 turns (Case 3)) are manufactured to study the starting and generating functions. The 5 turn stator machine is designed to have good characteristics at the starting torque and in generating. Case 2 


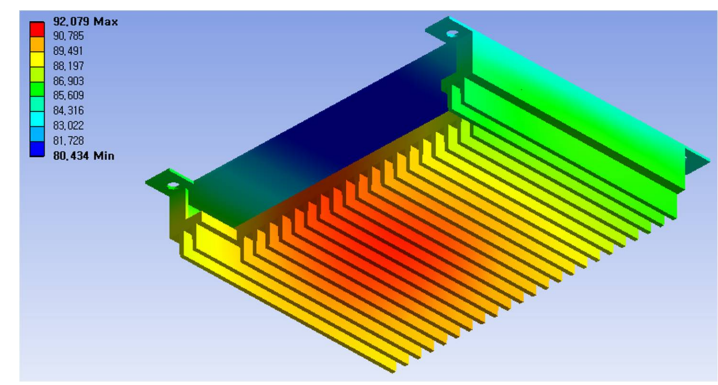

Fig. 7. Thermal analysis of the heat sink.
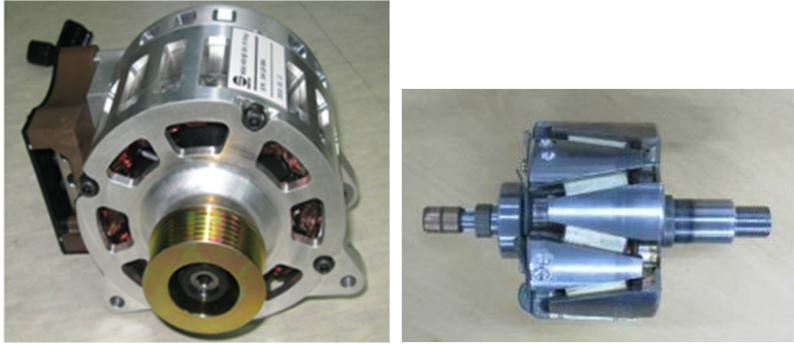

Fig. 8. Prototyped claw pole machine and rotor (with slip ring).

and Case 3 are designed to have good torque assist at 6,000 rpm.

A prototype claw pole machine and a rotor with s slip ring are shown in Fig. 8. It has a resolver to detect the rotor position and speed. The prototype controller and its power unit with a metal PCB are presented in Fig. 9 and Fig. 10, respectively. The shunt resistor $(0.1 \mathrm{mOhm}, 3 \mathrm{EA} /$ phase $)$ to measure the 3phase machine current, the snubber capacitor and the thermal sensor are installed at the metal PCB.

\section{B. Experimental Results and Design Consideration}

In Fig. 11, the experimental test results of the several types of claw pole machines with an ISG controller are presented. From Fig. 11(a), (b), the 4, 5 turn machines have good characteristics for starting (at low speeds) and generating (at all operation speeds) at the low super capacitor voltage $(16 \mathrm{~V})$. In the Case 2 machine, it satisfies the torque assist characteristics (5 N @ $6000 \mathrm{rpm}$ ) but it can not charge the super capacitor up to $27 \mathrm{~V}$ with a maximum field current when the speed is less than $8000 \mathrm{rpm}$. With the Case 2 machine, the 3-phase PWM converter operation (regeneration) is able to satisfy the continuous generating characteristic (1.2 $\mathrm{kW}$ electric power) but the electro motive force (EMF) is so low that the 3-phase PWM converter current is very high. It makes electromagnetic disturbances, converter losses and thermal problems in the heat sink during continuous operation.

The 3 5 turns stator coil machine has good characteristics in the starting mode and it operates well at low speeds as a synchronous rectifier. From 2000 rpm, the super capacitor can be charged by $27 \mathrm{~V}$ by conditioning the field coil exiting voltage as in Fig. 11(b). However, it can not help the engine as torque assist at high speed (refer to Fig. 11(a)). The flux weakening control can not overcome the excessive impedance voltage drop at high speed (the ISG was designed with 12 poles so that impedance voltage drop was very high).

Although the 1 and 1.7 turns coil machines can start the engine and the ISG was able to operate as a synchronous

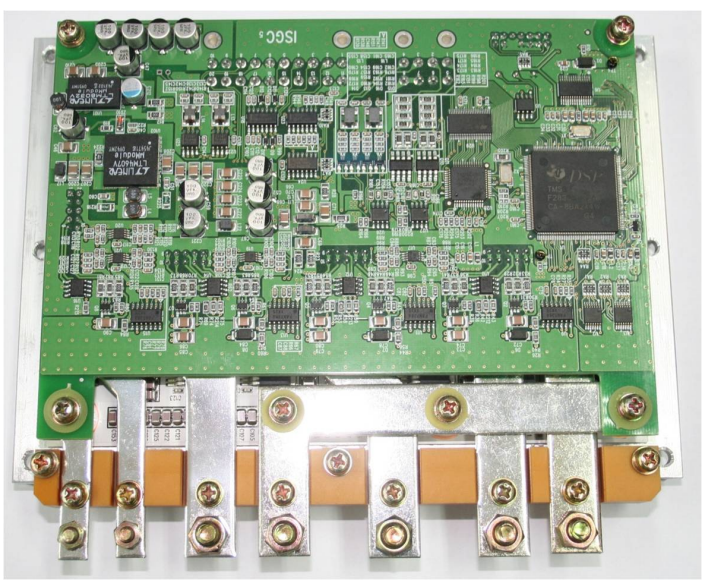

Fig. 9. Designed controller for ISG (27 V, $1000 \mathrm{~A})$.

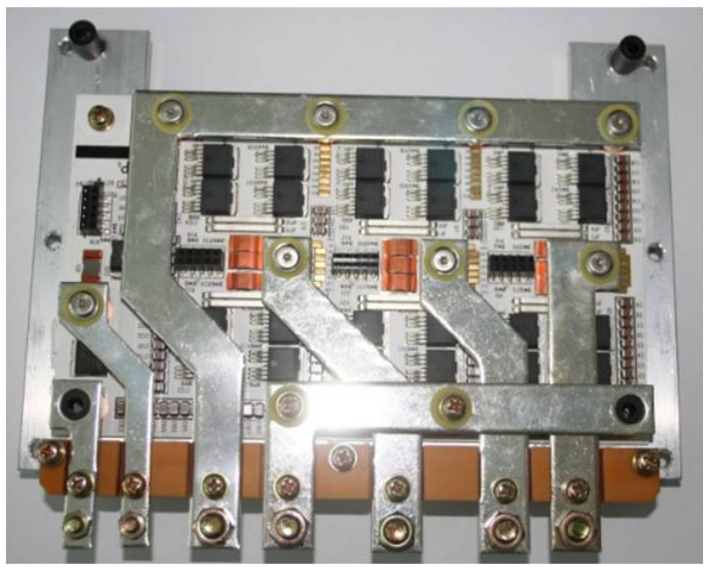

Fig. 10. Power unit with metal PCB (FET, shunt, snubber capacitor).

rectifier at high speed, it cannot charge the super capacitor by $27 \mathrm{~V}$ of nominal voltage due to the low EMF voltage with the maximum field current. Basically, the regenerative function allows for the recuperation of a vehicle's kinetic energy during braking phases. In the prototype, an attempt was made to operate the ISG as a PWM converter at low speed and as a synchronous rectifier at high speed. However, the generating power cannot meet the specification of $(4 \mathrm{~kW})$ in the 5,800 8,000 rpm region as shown in Fig. 13. It has a dead zone at a low super capacitor voltage (about $16 \mathrm{~V}$ ) because of the high impedance of the system (machine and line impedance). When the ISG is operated in the continuous generating function $(1 \mathrm{~kW}$ generation for the vehicle electric load after charging the super capacitor), the 3-phase PWM converter current is very high because of the low EMF. It deteriorates the heat sink and decreases the system efficiency.

\section{CONCLUSIONS}

It was very difficult to meet all of the operating modes (starting, generating, torque assist and regenerating) with the prototype ISG while the machine size is constrained so that it can be substituted for a the conventional alternator.

To improve the torque assist and the generating characteristics, at first, it was necessary to design a machine which has the low pole pair. This allow for the low operating frequency so that the inductance voltage drop will be minimized. Secondly, the rated DC voltage (super capacitor and machine voltage) 


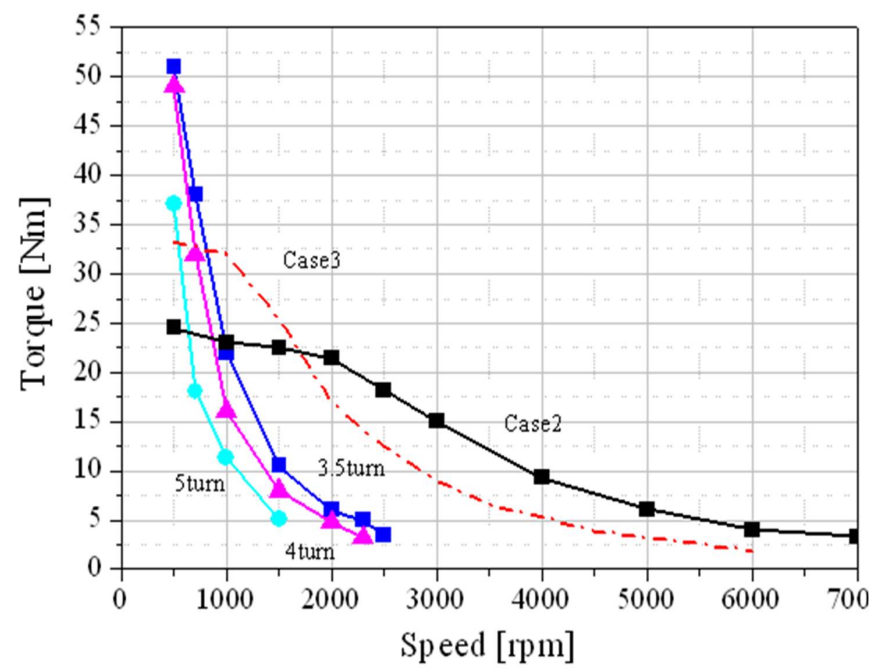

(a) Motoring characteristic (super capacitor $16 \mathrm{~V}$ ).

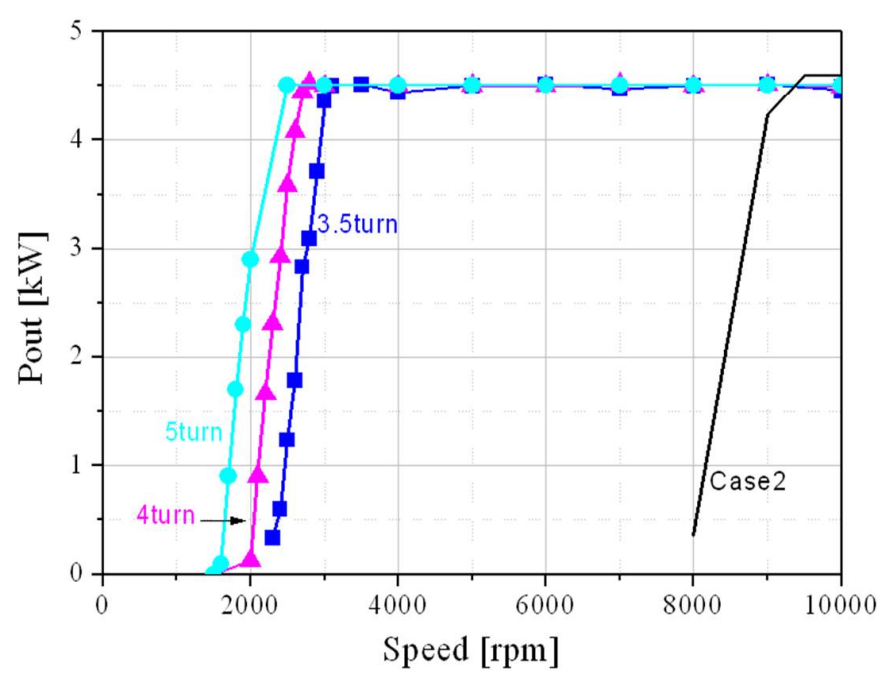

(b) $27 \mathrm{~V}$ generating characteristics (synchronous rectifier).

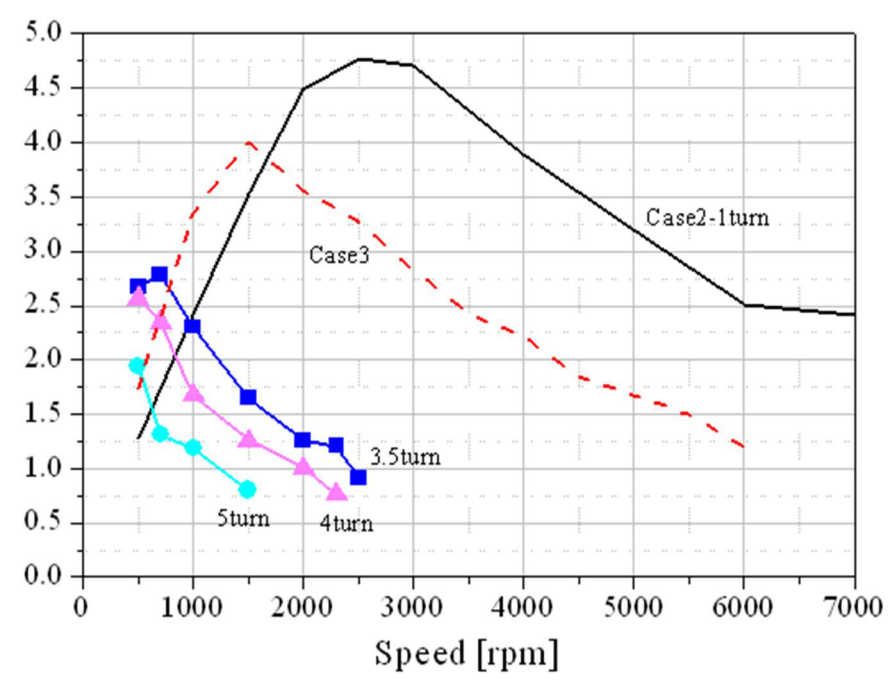

(c) Generating characteristic (super capacitor: $16 \mathrm{~V}$ ).

Fig. 11. A characteristic of the claw pole ISG according to stator turns.

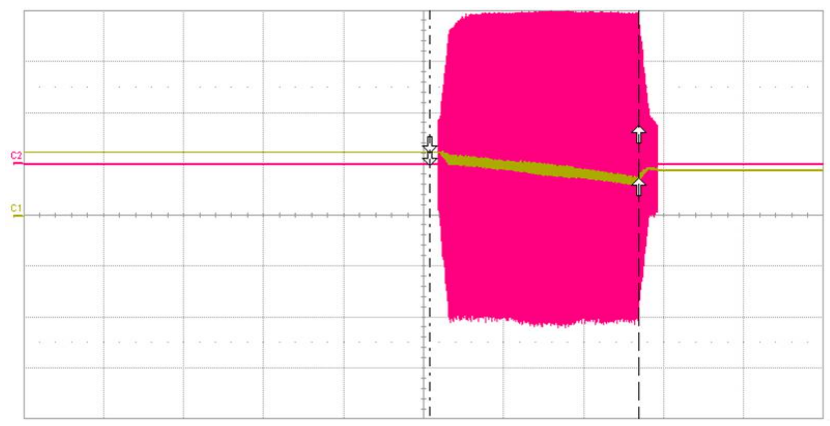

(a) Motor current [200 A/div, red], super capacitor voltage [20 V/div, yellow] at starting mode.

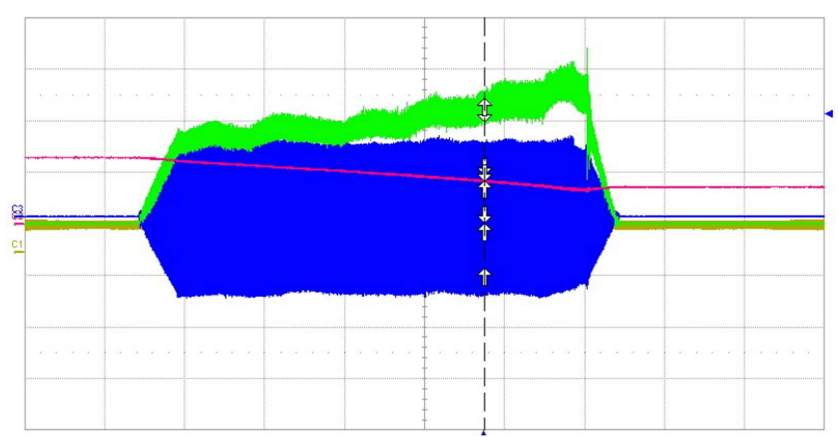

(b) Super capacitor current [100 A/div, green], motor current [100 A/div, blue], super capacitor voltage [20 V/div, red] at torque assist mode.

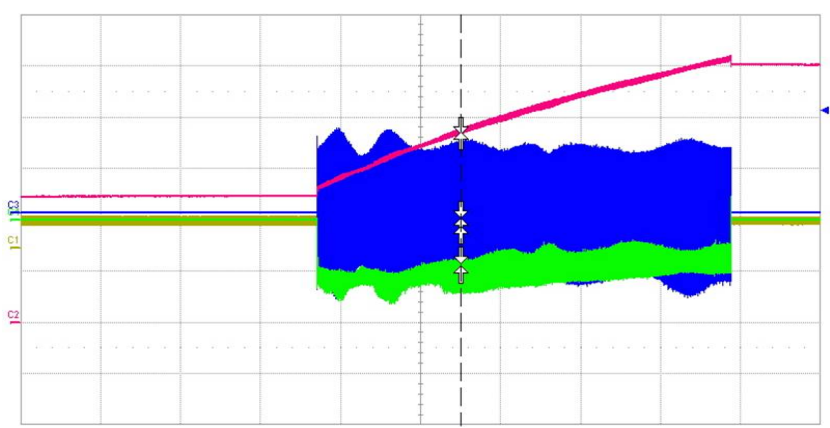

(c) Super capacitor voltage [5 V/div, red], motor current [200 A/div, blue], super capacitor current $[100 \mathrm{~A} / \mathrm{div}$, green] at generating mode (PWM converter operation).

Fig. 12. ISG characteristics of according to the operation.

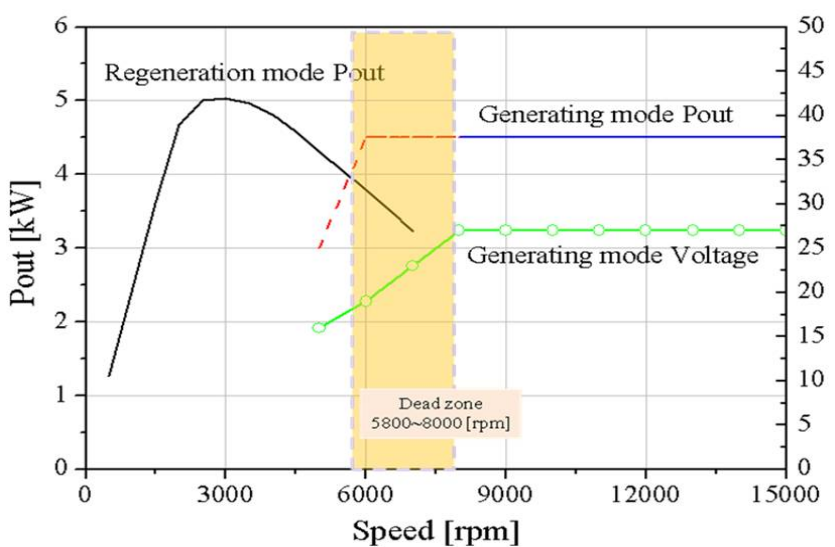

Fig. 13. Dead zone for $27 \mathrm{~V}$ generating (Case 2 machine). 
must be designed to ignore the parasitic impedance effect which exists in the super capacitor internal resistance and in the MOS-FET Rds, as well as the line impedance, etc. Thirdly, the field winding must be designed to adjust the EMF which is generated at low speed.

Form the view point of the ISG controller, the heat sink system adopts water cooling instead of fan cooling. Because of the high current at starting and during continuous regenerating (PWM converter mode), the shunt resistor which is adopted in the prototype ISG must be changed with a hall effect current sensor. In the high current, low voltage system like the prototype ISG, the line impedance between the super capacitor and the inverter results in a DC voltage fluctuation. Therefore, the super capacitor is installed near the controller and its impedance must be specially limited.

\section{ACKNOWLEDGMENT}

This work was supported in part by the research program 2011 of Kookmin University in Korea.

\section{REFERENCES}

[1] G. Friedrich and A. Girardin, "Integrated starter generator," IEEE Ind. Appl. Mag., Vol. 12, No. 4, pp. 26-34, Jul./Aug. 2009.

[2] J. E. Walters and R. J. Krefta, "Technology considerations for belt alternator starter systems," SAE World Congress, Mar. 2004.

[3] J. W. Jeong, G. H. Lee, and J. P. Hong, "Reduction design of vibration and noise in IPMSM type integrated starter and generator for HEV," IEEE Mag., Vol. 46, No. 6, pp. 2454-2457, Jun. 2010.

[4] J. Liu, J. Hu, and L. Xu, "Design and control of a kilo-amp DC/AC inverter for integrated starter-generator (ISG) applications," IEEE Industrial Applications Conference, pp. 2754-2761, Oct. 2004.

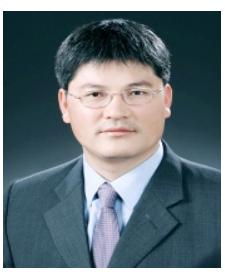

Geun-Ho Lee was born in Gyeongnam, Korea, in 1969. He received his B.S. and M.S. in Electrical Engineering and his Ph.D. in Automotive Engineering from the University of Hanyang, Seoul, Korea, in 1992 , 1994 and 2010, respectively. From 1994 to 2002, he worked for LG Industrial System where he developed inverter systems for elevators. Since 2011, he has been with the Graduate School of Automotive Engineering, Kookmin University, Seoul, Korea, where he is currently a Professor. His current research interests include the advanced control of electrical machines, and electric vehicles.

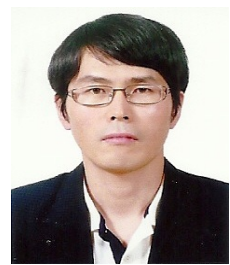

electric vehicles.

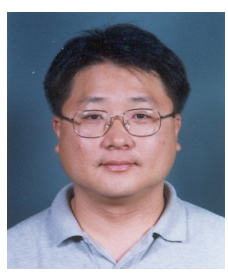

Woongchul Choi was born in Seoul, Korea in 1964. He received his B.S. in Mechanical Engineering from Seoul National University in 1987, and his M.S. and Ph.D. in Mechanical Engineering from Ohio State University in 1989 and 1995, respectively. He is currently a Professor in the Graduate School of Automotive Engineering, Kookmin University, Seoul, Korea. His current research interests include energy analysis and modeling for various types of electric vehicles including hybrid, fuel cell hybrid and pure electric vehicles, and system integration.

Geo-Seung Choi was born in Jeonnam, Korea, in 1974. He received his B.S. and M.S. in Electrical Engineering from Dong-A University, Busan, Korea, in 1998 and 2000 , respectively. From 2000 to 2009, he worked for automotive applications. Since 2010, he has been an Engineer at Samhyun. He is pursuing his Ph.D. in Electrical Engineering at Dong-A University. His current research interests include advanced motor control and 